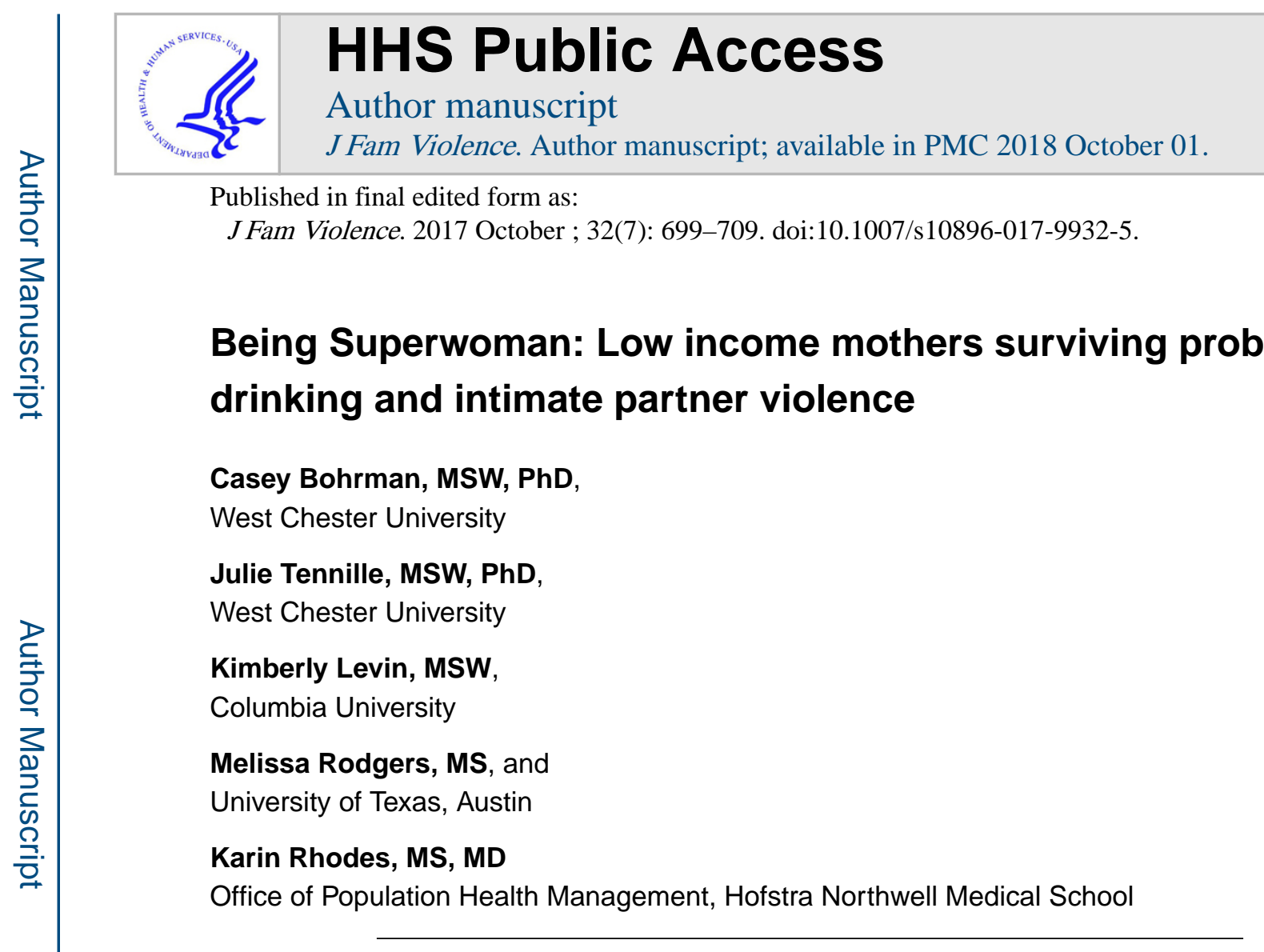

For some women, motherhood can provide purpose, an opportunity to better themselves, or at least the chance to provide an environment for their children that is preferable to what they experienced in their youth. For women struggling with substance use or violent relationships, motherhood can be an impetus to make positive changes (Edin \& Kefalis, 2005; Vatnar \& Bjørkly, 2008). However, motherhood can also compel women to remain in violent relationships or can create stressors that increase the risk of heavy drinking, which is defined by the National Institute on Alcohol Abuse and Alcoholism's sex-specific criteria, as four or more drinks per day (Baker \& Carson, 1999; Rhodes et al, 2010; US Department of Health and Human Services, 2005). While there is a high correlation between heavy drinking, also known as problem drinking, and interpersonal violence, the nature of this relationship is not yet fully understood (Fals-Stewart \& Kennedy, 2005). Researchers have yet to examine how motherhood might influence women's experiences of problem drinking and intimate partner violence.

\title{
Motherhood and Substance Use
}

Surprisingly, little information is available regarding the prevalence of problem drinking among mothers. Approximately $3.5 \%$ of women in the United States meet criteria for alcohol use disorder while they are pregnant, with slightly more than $7 \%$ of non-pregnant women meeting the same criteria (Vesga-Lopez, Blanco, Keyes, Olfson, Grant, \& Hasin, 2008). Research also indicates that approximately $10 \%$ of children live in a household where at least one parent is abusing substances, and researchers therefore have estimated that millions of mothers have substance use disorders (Substance Abuse and Mental Health Service Administration, 2011). While social use of alcohol is broadly condoned, excessive 
use by mothers of young children and any use by pregnant women is often interpreted as a sign of poor mothering (Finkelstein, 1994). A common perception of mothers who drink heavily or abuse other substances is that they are unaware of or do not care about how their behavior impacts their children.

Despite this perception, researchers have found that women who abuse substances are often aware of the negative effects on their children and blame themselves for being bad mothers (Baker \& Carson, 1999; Banwell \& Bammer, 2006; Ehrmin, 2001; Jacobs \& Jacobs, 2014). Ironically, these high levels of guilt and shame can sometimes serve as an impediment to seeking support (Ehrmin, 2001; Banwell \& Bammer, 2006). An additional barrier to reducing alcohol use is that some mothers perceive the calming effects of alcohol as allowing them to contend with the stressors of daily life and thus be better mothers (Baker \& Carson, 1999)

Conversely, other research suggests that motherhood could help women recover from drug and alcohol abuse. Edin and Kefalis' (2005) ethnography of low-income women in the Philadelphia area found that motherhood motivated many young women to return to school, seek a job, and become sober from drugs and alcohol. While these women were not always able to achieve their aspirations, their children kept them motivated. Balan and colleagues' (2014) found that motherhood generally reduces the rate of alcohol use disorder in women. They hypothesized that the reduction resulted from social controls being placed on mothers and mothers having less time to drink. However, when they broke their sample down by race, controlling for income, they found that for black women, motherhood did not reduce rates of alcohol use disorder. This was surprising because black women generally have lower rates of alcohol use disorder than white women (Grant et al 2004; Wilsnack, Klassen, Schur, \& Wilsnack, 1991).

In comparing black and white mothers, Balan and colleagues (2014) suggest that black mothers may experience the onset of alcohol use disorder at a later age than whites with alcohol use disorder. They also found that unlike white women, black women's perceived stress and discrimination were greater predictors of alcohol use disorder than family history. Taken together these findings may indicate that perhaps motherhood or other life stressors may be playing a greater role in problem drinking for black women than for whites. Additionally black mothers with racially segregated social networks were at particularly high risk of alcohol use disorders. The authors propose that racially-mixed networks may allow black mothers access to social and financial resources possessed by more privileged groups. They conclude that further research is needed to better understand the relationship between motherhood and drinking, particularly as is varies by race.

\section{Motherhood and IPV}

In examining the role that motherhood plays in substance use, it may also be helpful to consider that women engaged in substance abuse experience higher rates of intimate partner violence (IPV) than those without substance abuse issues (Cunradi, Caetano, \& Schafer, 2002). One of the most significant challenges faced by women in violent relationships attempting to be good mothers is the normative western cultural perception that being a good 
mother involves having a husband or at least a male partner in the home (Roberts, 1992; May, 2008). Therefore, a woman may stay in a dangerous relationship or at least remain in contact with her abuser for what she believes to be the benefit of their children. Additionally, women striving to be good mothers can feel pressure to remain in a relationship, as leaving a partner can involve uprooting children's lives, including exposing them to economic risks (Rhodes, Cerulli, Dichter, Kothari, \& Barg, 2010).

Women who decide that the safety risks to children outweigh the benefits of having a husband or a male partner in the home must contend with the added risk of help-seeking. In their study of mothers' decisions to leave violent relationships, Rhodes and colleagues (2010) found that women were afraid to seek help from formal social service systems for fear of exposing their children to the child welfare or criminal justice systems. Additionally, women who chose to leave violent relationships were at greater risk of harm, which could ultimately interfere with their ability to care for their children. In essence, women in violent relationships are constantly forced to choose from a range of poor alternatives.

\section{Feminist Standpoint Theory}

Women engaged in heavy drinking and in violent relationships may face high levels of stigma (Goode, 2000; Lapierre, 2008; Neger \& Prince, 2015). In order to gain their perspective, it is crucial to approach their situation through a nonjudgmental lens, rather than assume pathology. Feminist standpoint theory views knowledge as being situated within a context and privileges the voice of women with a particular experience, such as being involved in a violent relationship. We use this theoretical framework in our examination and interpretation of narratives offered by mothers who are both heavy drinkers and involved in abusive relationships (Hekman, 1997). Standpoint theory extends beyond examining the perspectives of particular women. Instead, “...standpoints are said to be achieved through a critical, conscious reflection on the ways in which power structures and resulting social locations influence knowledge production" (Intemann, 2010, p. 785). In specific, this framework allows for the exploration of women's views of their substance use and interpersonal relationships in the context of being mothers in a particular historical and social setting, such as the current political climate, the community context, and the ways in which certain groups experience privileged identities.

Hill-Collins (2002), credited with advancing feminist standpoint theory to include a focus on intersectionality of women's identities, suggests that it is crucial to be aware of the ways in which race and social class may shape mother's experiences. Women experiencing intimate partner violence may be simultaneously experiencing structural violence, "sinful" social structures characterized by poverty and steep grades of social inequality, including racism and gender inequality (Farmer, 2004, p. 307). Structural violence can constrain women's choices, complicating decisions to make changes in their current situation (Rhodes et al., 2012). Therefore the overall goal of this qualitative study was to use a feminist standpoint lens to elucidate ways in which motherhood shapes the process and consideration of behavior change among a sample of urban, predominantly low-income black women dealing with the complexities of mothering while drinking and navigating violent relationships. 


\section{Methods}

\section{Recruitment}

The sample of 32 adult women for our study was derived from a randomized control trial that took place in two urban academic emergency rooms/trauma centers (Rhodes et al. 2015; Rhodes, Rodgers, Sommers, Hanlon \& Crits-Christoph, 2014). The parent study sought to assess effectiveness of a manualized motivational interviewing (MI) intervention for IPVinvolved women reporting problem drinking patterns at the time of their ED visit. Women patients between the ages of 18 to 64 who were perpetrators and/or victims of IPV (as indicated by a score of 1 or more on the CTS2S) and risky drinkers (AUDIT score of 4 or more were eligible for enrollment. Participants in the larger study $(\mathrm{N}=600)$ were randomized 2:2:1 to three groups; MI experimental intervention group $(\mathrm{n}=240)$, assessed control group $(\mathrm{n}=240)$, and a no-contact control group $(\mathrm{n}=120)$. The intervention was a 20-30 minute MI session focused on both IPV and problem drinking, recorded and monitored for fidelity, with a follow-up phone booster. Therefore only women randomized to the intervention group were eligible for the current study.

For the current study, we selected all mothers from the brief intervention group who were living with children under 18, consented to audiotaping, and were experiencing harmful or hazardous drinking and/or severe IPV relationships. The demographics of the sample are presented in Table 1. The final sample was composed of 32 women, mean age of 30 (range 15-53), more than three-quarters of whom were black. The majority were single and low to middle income (25\% making less than $\$ 10,000$ and only $3 \%$ making over $\$ 50,000$ annually), with slightly less than half of the sample employed outside of the home. Most of the women in the study presented in the ED for medical reasons, with only three presenting due to an injury, which may or may not have been due to violent relationships or alcohol use.

Table 2 presents the specific data regarding study eligibility as well as other psychosocial risk. As mentioned above, the sample for the current study was limited to mothers who either disclosed severe IPV ( 1 or more of the behaviors defined as severe on the CTS2S), or disclosed harmful or hazardous drinking behaviors (AUDIT score of 8 or more) (Reinert \& Allen, 2002; Strauss \& Douglas, 2004). Participants had to meet at least one of these more severe criteria to be eligible for our qualitative study; $28 \%$ met both of the criteria.

In terms of behavioral health co-morbidities, about half of the women in the study were also using illicit drugs. This group had extremely high rates of depression as measured by the Center for Epidemiological Studies-Depression10 (CES-D10) Scale (97\% meeting criteria for depression; score of 10 or greater) (Björgvinsson, Kertz, Bigda-Peyton, McCoy \& Aderka, 2013; Miller, Anton \& Townson, 2013). Slightly over one half of this sample screened positive for post-traumatic stress disorder as measured by The Primary Care PostTraumatic Stress Disorders Screener (Prins et al, 2003) as well as child sexual abuse measured by two binary questions from the Gender, Alcohol, and Culture: An International Study (Wilsnack \& Wilsnack, 2002). 


\section{Procedures}

This qualitative sub-study was approved as an amendment to the parent study by the University Of Pennsylvania institutional review board (IRB). The authors were all involved in the conduct of the parent study, where participants gave written permission for access to their protected health information and analysis of their recorded motivational interventions. The research team arranged for transcription of the selected audiotapes by a HIPAAcompliant transcription service and ensured the accuracy of the transcriptions by listening to all 32 audio recordings and comparing them line-by-line to transcriptions.

Since interviews represented a first meeting between patient and motivational interviewing therapist in the ED, the sessions typically centered around clarification of the women's perceptions of their drinking and relationship behaviors. The intervention was not an effort to convince women to stop drinking or leave relationships if the women did not view these behaviors as problematic (Miller \& Rollnick, 2012). As such, and if women exhibited an interest in change, open questions were posed and reflective listening was used by therapists with the aim of prompting participants to consider readiness, willingness, and ability to make drinking and relationship changes. Therefore, while therapists were not serving as objective interviewers, much of their process was similar to a semi-structured interview where researchers seek to elicit information from participants in a non-judgmental fashion. Thus, the topic of motherhood was not solicited but arose organically during these sessions.

\section{Data Analysis}

Two of the authors (insert authors' initials) were clinicians on the original study. They have extensive experience in clinical social work and received formal training and ongoing supervision in motivational interviewing throughout the study. Their social work practice orientation allowed them to go into the data analysis with a focus on individual strengths as well as multi-level environmental influences on each individual. They were able to provide methodological guidance to a third research team member involved in the analysis (insert author's initials), who also had a social work background. Research team members (insert authors' initials) began by familiarizing themselves with the data by listening to the tapes and reading through the transcripts, using analytic memos to note initial thoughts about the data (Ritchie \& Spencer, 2002). Next, we used line-by-line descriptive coding of sections of the sessions in which motherhood was mentioned (Corbin \& Strauss, 1990). The descriptive codes utilized participants' language in order to best represent their perspective. The codes were examined for themes, and the data were re-coded using the emerging themes (Braun \& Clark, 2006). Themes were driven by the raw data and not a priori theory. This method enabled us to discover patterns, commonalities, and differences among participant narratives by remaining close to the women's words (Braun \& Clark, 2006). We then examined these codes within the context of feminist standpoint theory, critically examining how their perspectives could have been shaped by their social and historical contexts (Hekman, 1997). Women in this study experienced poverty, intergenerational mental health and substance use issues, and chaotic living environments. We carefully examined how these contextual issues impacted their perspectives about motherhood, drinking and intimate partner violence. 
To ensure analytical rigor, we employed triangulation, peer debriefing and negative case analysis (Padget, 1998). The research team employed triangulation by having at least two people code each interview at every stage of the coding process. During the first round of coding, the two researchers employed line by line coding until they reached theme saturation, a point where no new codes were emerging. After the first round of coding, the two researchers involved in coding met to discuss and resolve differences in codes. We worked together to identify emerging themes among the codes. We then met with a third team member to go over original codes and how we identified emerging themes. Next, we coded the data with the emerging themes and compared our use of themes, looking for any data that did not fit within themes or seemed to contradict a theme. We used these negative cases to refine our themes. Through a process of peer debriefing, the third team member identified places where the codes aligned with the themes or perhaps required new themes or a refinement in the definition of a theme. Throughout the process, the research team utilized coding and theoretical memos in order to document changes during the analysis (Strauss \& Corbin, 1994).

\section{Findings}

When we initially approached the analysis, we narrowly focused on the dyadic relationship between the mother and child. However, feminist standpoint theory required us to examine this relationship within a broader social context. Refinement of our codes into themes, led us to see that the impact of children on these women's thoughts and behaviors could only be understood within the context of a social support system that lacked resources. With few people on which to depend, they were challenged to balance their own needs with the competing needs of others, including those of their children. While women indicated that children provided motivation to reduce or discontinue the use of alcohol, there were a myriad of countervailing factors compelling the women to drink. For example, it was difficult for women to abstain from alcohol because they were often surrounded by drinkers in their home and social lives. Likewise, financial struggles in combination with having social networks with limited resources made it difficult to escape these challenging environments. Constant struggles and self-criticism often contributed to depression, which detracted from their ability to manage multiple tasks and roles. Women sought to be good mothers and role models for their children, which generally resulted in the desire to reduce drinking. However, the normative pressure to remain connected to abusive partners for the sake of their children often prevented exit from abusive relationships. Due to the environmental stressors, including those related to their partners, women used alcohol to manage the stress. The following sections present themes depicting ways that parenthood impacted drinking and decisions to leave violent relationships within a context of limited social support. The overall theme that emerged from the data was Being Superwoman. Within that supercode were two categories: The first, Being a good mother, with sub-themes of Children as ties to partner and What I've been raised around, the second, category being Managing it all alone. In the presentation of the data we have assigned participants numbers 1-32 to protect their identities. 


\section{Being a good mother}

Many of the women were determined to change their behavior and relationships in order to serve as better role models for their children. More specifically, within the transcripts, "role models" and "examples" were specific codes which were then extrapolated into this theme through analysis. Often when women would mention serving as a role model/example, it was brought up in the context of that idea being a catalyst for change. However, for some women, this study was the first time that they had the space to make connections between drinking behavior and its impact on their children. Participant 21 made the connection midsentence:

As far as my daughters is concerned, it never really affected them too much but it probably could have if I continued on drinking. Yeah it does, it was affecting my daughter because she was always late for school in the morning because I didn't want to get up. So it did affect my oldest daughter.

Later, during the session, she commented, "It's interesting because it was impacting her but it's easy when you are caught up in it not to necessarily realize this long list of things, this long list of ways it impacted you." She went on to discuss how she wanted to stop drinking to be a role model for not only her children, but also her younger sister.

Other women identified that they needed to stop drinking for their children. In discussing why she was no longer drinking, participant 5 said, "That's the only way I can have a life; that's the only way I can have a future. It's the only way my kids can have a future."

Participant 27 noted that her drinking was getting in the way of her achieving other goals and that this would ultimately impact her child.

The only way to change it is to change my behavior and I didn't really wanna face that, but it's getting to a point where I got to because I have a child that depends on me. My family is depending on me kind of. I wanna go get my education, but I can't get that if I'm still drinking, being an alcoholic. I don't wanna be an alcoholic.

While many of the women wanted to reduce or stop their drinking because of their children, their desire did not always lead to behavioral change. Participant 2 talked about how she tried not to drink in front of her son, but did so occasionally. However, she was vigilant about reminding her son not to drink. She said,

I guess and I taught him, he knows what an adult beverage is, so he will even say are you drinking an adult beverage, and I'm like yeah I'm having an adult beverage and he say well I don't want any of that.

\section{Being a good mother: Children as ties to partner}

A common theme throughout these interviews was the tendency of the women to put their children's interest above their own. While there were a few cases of women who left violent relationships to protect their children, children more often served as ties to a partner. While the women genuinely wanted to behave in ways that would benefit their children, they also were motivated by the fear that others would perceive them as bad mothers if they cut ties with their partners. Participant 10 said, "And I feel so bad because they say if I don't have no contact with my son's father, then I'm a bad mother." 
Participant 26 was also conflicted about leaving her partner because she did not want to be stigmatized as a single mother:

It's just funny because I just had a son, I got a six month old so who wants to have kids by someone and not raise them together? It just, I don't know, I didn't wanna be another statistic, but things happen.

Women reported that their partners took advantage of their willingness to maintain contact for the sake of their children. Others cited that their abusive partners used the children to exert control over the women. Participant 24 said,

My son was at school and his TSS [therapeutic support services] worker was supposed to pick him up and his TSS worker wind up callin' me, tellin' me that he [the father] was there about to pick up my son. I'm like, he ain't supposed to, like we not talkin'. He got my son, tried takin' my son, in order for me to talk to him, to bring my son to me in order for me to talk to him.

\section{Being a good mother: What l've been raised around}

The women's construction of being a good mother was perhaps influenced by experiences with their parents. Participant 11 said,

I mean we been through a lot where he put up with my problems, I put up with his problems. Sometimes his problems may override my problems and I get looked at like how do you deal with that, but it's how I been raised, what I been raised around. I haven't been raised around my mom leaving one person because of their small issue to the next to the next. My mom has been married for almost 11 years now so it's like I would watch this.

However, most women wanted to raise their children differently from how they were raised. Participant 12 said,

I been moving around ever since I can remember it's always been me, the person like who is holding the household together, or we lose a home, we always constantly getting evicted, constantly lights being turned off, without water, gas, and like I'm just, like I said, again, I'm just getting older and got my kids too. I'm just getting tired of it.

They also referenced times when their own mothers or fathers were drunk in front of them and expressed fears that their children might recognize their substance abuse problems. Participant 21 said,

Because my grandfather was an alcoholic, I'm thinking my mother was alcoholic, my aunt. I just had a birthday party on Saturday, it was like, I was looking at her and it was like I'm was like that, like I ordered wine after wine after wine. So I think it like runs in my family maybe.

The women also made connections between observing their parents in violent relationships and the interpersonal violence they were currently experiencing. Participant 8 noted,

I seen my mom throw a 24 inch TV down the third story of the house to my dad and miss him by this much. You know what I mean...I remember it was about to 
rain. I remember everything. I even remember what my mom had on that day. Like I don't want my daughter remember all that about us.

Their parents' behaviors shaped their own childhood but sometimes also served as stressors in their adult lives. Participant 19 stated,

My mom been addicted to drugs all my life. I still take care of her and at the end of the day I drink because it's hard being....everybody. I am everybody. I am like ten people in one. I gotta be a daughter to my mom and then my mom and my dad not together so I gotta be a daughter to him too.

One of the themes from the transcripts was that the women were striving to be better mothers than the examples that they had from their own childhood-doing it better for their children than they feel they had was a prominent pattern seen across many of the transcripts.

\section{Managing it all alone}

The women provided support to others, but had few people to support them. Seeing their parents struggle with poverty, substance use, and other challenges, the women in the study did not want to be another burden on their family members. They were also hesitant to rely on friends for help and preferred to deal with their problems on their own. Participant 11 said "...I keep it bottled in sometimes because I don't want to always tell everyone my same problems. People get tired of hearing the same thing."Sometimes the women avoided talking to others for fear of being judged, particularly when they had compassion for or tried to understand their abusers. Participant 25 stated,

...People, they just judgmental. They don't know stuff that he probably went through in his life the way I do, cause I know him and we talk and we actually had conversations about things that had happened in his life, so people don't know and it's not my place to tell people or try to explain why he act the way he do, but things happen in his life and I think that's where it comes from.

Lack of substantive social support made it difficult for some women to leave their relationships. They often relied on their partners for financial support and housing. Some said that if they decided to leave, they could go to a friend's or family member's home, but others knew they would be forced to go to a shelter. That was a frightening prospect for women who had never before lived in a shelter. One woman discussed concerns over what it would be like to share a space with strangers. Participant 12 said,

I'm a neat freak and I don't like people touching my things like even at my home, my door is locked. I have things in my room. I don't like people wearing my clothes, I don't...I don't know, I just like my things to myself and as far as that, like, I know I'm gonna have to go to the shelter so I have to really set my mind mentally to be ready for that.

Even when other people reached out to provide support to the women in the study, some were unable to take advantage of the support. Participant 19 noted,

My neighbor she wants to be friends with me so bad, and she is a very nice person, but I just don't have no more room in my life for not one more person. I just don't 
feel like there's a space for you to go. Everybody's got they own little spaces. This is what I had to do with all these people. I had to put them all in like frickin' little pouches. You go in this compartment. You go in that compartment. You stay in this pouch and you go down there in that pouch.

\section{Being Superwoman}

Finding time to address their own needs was one of the biggest challenges women faced in making changes. The code of being superwoman was somewhat of an overarching code in that it encompassed the themes needing to be everything to everyone. The women talked about how difficult it was to manage everyone's needs. Participant 8 stated:

I don't know where it written that the baby got to keep everybody together, it suppose to be the oldest, but in my situation, it's always me. Everything always falls on me. There are so many obligations that it can be difficult to manage them all. I'm like OK, my momma is sick, she needs this, but my baby does need this I need to take care of both of them. They're on the same level, ain't know who comes first.

The women provided support not only to family members, but also to their friends. In discussing how much she does for others, Participant 19 compared herself to a super hero.

I have two best friends and they're both guys. They're needy, like a mutha'. Women don't realize how needy men are. Men are so frickin' needy. It's ridiculous. So it's like at the end of the day I'm a superwoman.

The need to provide emotional and material social support for others even served as a barrier to leaving abusive relationships. Participant 10 talked about moving to California to get away from her partner but having to return to help her family.

My great grandmother had passed away and everything they needed me to come back. I had to leave a job that I liked and everything so it wasn't like I wanted to go back because it kinda looked like things were ok.

So, while other mothers struggle because they constantly place their children's needs above their own, women in this study also prioritized the needs of their friends and families above their own. They felt forced to take their limited resources and divide them sparingly among everyone who depended upon them.

\section{Discussion}

The purpose of this study was to understand how motherhood impacted women's thoughts and behaviors around problem drinking and violent relationships. Feminist standpoint theory helped us to understand these dynamics within a broader context of sexism, social networks with few resources, and while not directly mentioned by the women in the study: racism. Patriarchal forces put intense pressure on women to be ideal mothers, meaning that their entire lives revolve around their children (Arendell, 2000; Hays, 1996). Indeed, women in this study also strove to be good mothers as evidenced by their focus on being role models for their children. However, attempts at being 'Superwoman' by keeping children's fathers involved, shouldering the burden of caring for aging parents, friends, and others in their 
social network, were costly and overwhelming, making it unclear as to whether aspirations of being a role model translated into behavior change. While children may have provided motivation to reduce or discontinue the use of alcohol, there were a myriad of countervailing factors compelling the women to drink.

While we approached the analysis with a focus on motherhood, we found that broader caretaking responsibilities for other people in these women's lives also played a critical role in limiting opportunities to focus on themselves. This finding points to women feeling pressure not only to be a "good mother," but to more generally be a "good woman." In her longitudinal study of women with depression, Jack (1991) found that being a "good woman" meant prioritizing relationships and the needs of others while subordinating your own needs. Being superwoman, the over-arching code in our study, shows that the women in our study felt that they needed to be more than good women; they needed to be superwomen. The pressure to be a strong woman may have been particularly great for the black women in the study, given historical tropes and pressures on black women to be the head of the family (Hill-Collins, 2002). Prioritizing needs of others can be constructed as weakness and even labeled "co-dependency," which ignores how patriarchal structures pressure all women to behave in this way (Anderson, 1994). While labeling the women's efforts to help others as pathological may not be helpful, this research underscores the importance of not downplaying ways these perceived obligations limited opportunities to focus on their own health and well-being.

One of the greatest challenges the women in this study faced was the view that their support for others, including other women, was not reciprocated, in essence they had no one to rely on. Based on the data available, we have no way of discerning what type of support was actually being offered to these women, however feminist standpoint theory suggests that the women's perceptions of the situation hold important value. Research on the benefits of social support in mitigating the stresses of motherhood, reducing drinking, and leaving violent relationships has found mixed results (Burchinal, Follmer, \& Bryant, 1996; Katerndahl, Burge, Ferrer, Becho, \& Wood, 2013; Hashima \& Amato, 1994). Others have suggested that the reasons these findings are so varied may be that the quality of social support available to women varies by income, women's social situations, perceptions of discrimination, and racial segregation (Balan et al, 2014; Belle, 1990; Hawkins, 2010; Raikes \& Thompson 2005). Additionally, many studies examining the impact of social support have failed to consider both the positive and negative dimensions of support (Raikes \& Thompson, 2005). Even when women do have strong social support networks, some available support may not be helpful. For example, in research by Trotter and Allen (2009) on women in violent relationships, $78 \%$ of women characterized their network as being a mix of helpful and unhelpful support. The women in that study also discussed experiencing judgment and emotional unavailability from people in their social network, which closely mirrors the way women in our study discussed their social networks.

For low-income women, social networks may not only fail to provide buffers for stress, but they may actually serve as further sources of stress (Hawkins, 2010; Mulia, Schmidt, Bond, Jacobs, \& Korcha, 2008). Belle and Doucet (2003) conducted a review of literature on poor women's social networks that led them to conclude that the costs associated with those ties 
outweigh the benefits. Because the social networks of poor women tend to be filled with other people in similarly tenuous conditions, they may take on additional stress through a process of stress contagion (Wilkins, 1974). In a study of low-income single mothers, Hawkins (2010) found that while social networks could provide practical help and encouragement, they also could discourage women from making changes, increase their level of responsibilities, and serve as a distraction, preventing them from focusing on longterm goals. These findings suggest that practitioners should be cautious in creating treatment plans that rely heavily on the resources in the women's natural support systems.

\section{Limitations}

As a qualitative study of 32 women in one urban area, the major limitation is that results are primarily hypothesis generating and not generalizable to the broader population. However, the intimate nature of the study recordings, which took place in a nonjudgmental therapeutic context, allowed for an in-depth understanding of forces shaping thoughts and behaviors of mothers struggling with IPV and problem drinking. Research with larger sample sizes should examine ways in which drinking increases or decreases during motherhood, how drinking patterns may change as children age, as well as how the construction of ideal motherhood serves as a barrier to seeking and obtaining help for substance abuse and domestic violence.

Balan and colleagues (2014) suggested that black and white mothers may have different drinking experiences. Because our sample was relatively homogenous in terms of race, we were unable to examine racial differences in experience. Future studies should explore this distinction as well as the experiences of mothers of other races and ethnicities.

This study did not focus on the role of drug abuse, which may further complicate the recovery process and could potentially influence women's perceptions of their situations. Future research is needed to examine the co-morbid role of illicit drug abuse among women experiencing both IPV and problem drinking.

Another limitation of our study is that data were gathered through the analysis of MI therapy sessions that were specifically focused on IPV and drinking and not designed to explore the influence of motherhood. Therefore, our information on motherhood in the context of problem drinking and IPV is limited to that which was volunteered by women without specific prompting. Yet, embedded in these stories are roadmaps to future research on the complexities of mothering while drinking and navigating violent relationships. For many women in our study, motherhood was laden with expectations and pressure, frequently presented in an idealized manner. Participants may have felt compelled to speak about motherhood in a socially desirable fashion or, alternatively, may have shared the normative views they are struggling to live up to. However, because women spoke about motherhood of their own accord, not as a focal point of the study, narratives may actually have been more candid, authentic, and less guarded, allowing us the privilege to hear their genuine perspectives. However, a future study focused on explicitly asking women about their perceived relationship between motherhood, substance use, and IPV, would allow greater understanding of the women's unique understanding of these dynamics. There is an 
additional concern that the intervention format could have influenced the women to be more optimistic about the possibility of behavioral change, however this bias may be present in any study when people are aware of the focus on research (Fisher \& Katz, 2008).

\section{Implications}

If practitioners want to work with women, particularly low-income mothers, to address intimate partner violence and substance use, they should be cognizant of ways such issues interact with structural forces such as poverty, sexism, and poor access to housing. One way that these topics can be addressed is in the context of a therapeutic intervention. In an analysis by Lafrance and Stoppard (2006) of narratives of women who had recovered from depression, they found that the women's ability to abandon ideas of how they 'should' behave as women was key to recovery. In fact, in order to recover from depression, women had to learn to say "no" to others and focus on self-care. Given that almost all of the women in our sample also met criteria for depression, it seems relevant to suggest further study to determine whether narratives that help women understand how behavior is constrained by societal norms would be helpful in addressing issues such as heavy drinking and intimate partner violence.

Interventions such as motivational interviewing and narrative therapy, a counseling approach that helps people to re-author their life stories and challenge cultural constructions of what it means to live well, could be used to build on their core value of being a role model for their children and use that as an effective impetus for change (White \& Epston, 1990). Such counseling approaches embody a spirit of non-judgment, curiosity, strengths-focus, and rejection of dominant discourses that serve to oppress rather than empower. Indeed, Brosi and Rolling (2010) found that narrative therapy was helpful for women in violent relationships to make the conceptual transition from victim to survivor. However, they also note that those without helpful social supports were not always able to leave violent relationships.

While work is needed at an individual level to help women address domestic violence, there is a simultaneous obligation to focus on the structural violence, like racism, sexism and poverty, impacting women like those who participated in our study. Providers need to be aware of the toll exacted by daily micro-aggressions and examine ways in which racism and sexism may impact policies from both governmental and agency levels (Nadal, Griffin, Wong, Hamit, \& Rasmus, M. 2014). Training providers to work more collaboratively and nonjudgmentally with women experiencing challenges such as problem drinking and intimate partner violence may reduce environmental and structural barriers that prevent people from accessing services. Creating change at the health care workforce/organizational level with greater capacity to deliver empowering evidence-based services, including such services as MI, may in the aggregate, represent a structural intervention (Blankenship, Friedman, Dworkin, Mantell, 2006). Other structural interventions, such as providing women with stable housing, are another integral component of addressing structural violence. While alcohol and other intoxicants can contribute to the likelihood of experiencing violence, they can also dull the daily pain of experiencing violence (Abramsky 
et al., 2011; Leonard, 2005). Multi-level approaches are necessary to build on women's strengths while simultaneously removing barriers to recovery and safer relationships.

\section{References}

Abramsky T, Watts CH, Garcia-Moreno C, Devries K, Kiss L, Ellsberg M, ... Heise L. What factors are associated with recent intimate partner violence? Findings from the WHO multi-country study on women's health and domestic violence. BioMed Central Public Health. 2011; 11(1):109. [PubMed: 21324186]

Anderson SC. A critical analysis of the concept of codependency. Social Work. 1994; 39(6):677-685. [PubMed: 7992137]

Arendell T. Conceiving and investigating motherhood: The decade's scholarship. Journal of Marriage and Family. 2000; 62(4):1192-1207. DOI: 10.1111/j.1741-3737.2000.01192.x

Associated Press. PA to end cash assistance program. Reading Eagle. 2012 Aug 6. Retrieved from: http://www2.readingeagle.com/article.aspx?id=396036

Baker PL, Carson A. "I take care of my kids": Mothering practices of substance-abusing women. Gender \& Society. 1999; 13(3):347-363. DOI: 10.1177/089124399013003005

Balan S, Widner G, Chen HJ, Hudson D, Gehlert S, Kato Price R. Motherhood, psychological risks, and resources in relation to alcohol use disorder: Are there differences between black and white women? International Scholarly Research Notes Addiction. 2014; :1-9. Article ID 437080. DOI: $10.1155 / 2014 / 437080$

Banwell C, Bammer G. Maternal habits: Narratives of mothering, social position and drug use. International Journal of Drug Policy. 2006; 17(6):504-513. DOI: 10.1016/j.drugpo.2006.09.005

Belle D. Poverty and women's mental health. American Psychologist. 1990; 45(3):385-389. DOI: 10.1037/0003-066X.45.3.385

Belle D, Doucet J. Poverty, inequality, and discrimination as sources of depression among U.S. women. Psychology of Women Quarterly. 2003; 27(2):101-113. DOI: 10.1111/1471-6402.00090

Björgvinsson T, Kertz SJ, Bigda-Peyton JS, McCoy KL, Aderka IM. Psychometric properties of the CES-D-10 in a psychiatric sample. Assessment. 2013; 20(4):429-436. DOI: 10.1177/1073191113481998 [PubMed: 23513010]

Blankenship KM, Friedman SR, Dworkin S, Mantell JE. Structural interventions: concepts, challenges and opportunities for research. Journal of Urban Health. 2006; 83(1):59-72. DOI: 10.1007/ s11524-005-9007-4 [PubMed: 16736355]

Braun V, Clarke V. Using thematic analysis in psychology. Qualitative Research in Psychology. 2006; 3(2):77-101. DOI: 10.1191/1478088706qp063oa

Brosi MW, Rolling ES. A narrative journey for intimate partner violence: From victim to survivor. The American Journal of Family Therapy. 2010; 38(3):237-250. DOI: 10.1080/01926180902961761

Burchinal MR, Follmer A, Bryant DM. The relations of maternal social support and family structure with maternal responsiveness and child outcomes among African American families. Developmental Psychology. 1996; 32(6):1073-1083. DOI: 10.1037/0012-1649.32.6.1073

Corbin JM, Strauss A. Grounded theory research: Procedures, canons, and evaluative criteria. Qualitative Sociology. 1990; 13(1):3-21. DOI: 10.1007/BF00988593

Cunradi CB, Caetano R, Schafer J. Alcohol-related problems, drug use, and male intimate partner violence severity among US couples. Alcoholism: Clinical and Experimental Research. 2002; 26(4):493-500. DOI: 10.1111/j.1530-0277.2002.tb02566.x

Edin, K., Kefalas, M. Promises I can keep: Why poor women put motherhood before marriage. Oakland, Ca: University of California; 2005.

Ehrmin JT. Unresolved feelings of guilt and shame in the maternal role with substance-dependent African American women. Journal of Nursing Scholarship. 2001; 33(1):47-52. DOI: 10.1111/j. 1547-5069.2001.00047.x [PubMed: 11253579]

Fals-Stewart W, Kennedy C. Addressing intimate partner violence in substance-abuse treatment. Journal of Substance Abuse Treatment. 2005; 29(1):5-17. DOI: 10.1016/j.jsat.2005.03.001 [PubMed: 15979527] 
Farmer PE. An anthropology of structural violence. Current Anthropology. 2004; 45(3):305-325. doi: 0011-3204/2004/4503-0001.

Finkelstein N. Treatment issues for alcohol-and drug-dependent pregnant and parenting women. Health \& Social Work. 1994; 19(1):7-15. [PubMed: 8168782]

Fisher RJ, Katz JE. Social desirability bias and the validity of self-reported values. Psychology and Marketing. 17(2):105-120.

Grant BF, Dawson DA, Stinson FS, Chou SP, Dufour MC, Pickering RP. The 12-month prevalence and trends in DSM-IV alcohol abuse and dependence: United States, 1991-1992 and 2001-2002. Drug and Alcohol Dependence. 2004; 74(3):223-234. DOI: 10.1016/j.drugalcdep.2004.02.004 [PubMed: 15194200]

Goode S. Researching a hard-to-access and vulnerable population: some considerations on researching drug and alcohol-using mothers. Sociological Research Online. 2000; 5(1) Retrieved from http:// www.http://www.socresonline.org.uk/5/1/goode.html.

Hashima PY, Amato PR. Poverty, social support, and parental behavior. Child Development. 1994; 65(2):394-403. DOI: 10.2307/1131391 [PubMed: 8013229]

Hawkins RL. Fickle families and the kindness of strangers: Social capital in the lives of low-income single mothers. Journal of Human Behavior in the Social Environment. 2010; 20(1):38-55. DOI: $10.1080 / 10911350903183263$

Hays, S. The cultural contradictions of motherhood. New Haven: Yale University Press; 1996.

Hekman S. Truth and method: Feminist standpoint theory revisited. Signs: Journal of Women in Culture \& Society. 1997; 22(2):341-365.

Hill Collins, P. Black feminist thought: Knowledge, consciousness, and the politics of empowerment. New York: Routledge; 2002.

Intemann K. 25 years of feminist empiricism and standpoint theory: Where are we now? Hypatia. 2010; 25(4):778-796. DOI: 10.1111/j.1527-2001.2010.01138.x

Jacobs L, Jacobs J. 'Bad' mothers have alcohol use disorder: Moral panic or brief intervention? Gender and Behaviour. 2014; 12(1):5971-5979. DOI: 10.1037/t01528-000

Jack, DC. Silencing the self: Women and depression. Cambridge, MA: Harvard University Press; 1991.

Katerndahl D, Burge S, Ferrer R, Becho J, Wood R. Differences in social network structure and support among women in violent relationships. Journal of Interpersonal Violence. 2013; 28(9): 1948-1964. DOI: 10.1177/0886260512469103 [PubMed: 23262818]

Lafrance MN, Stoppard JM. Constructing a non-depressed self: Women's accounts of recovery from depression. Feminism \& Psychology. 2006; 16(3):307-325. DOI: 10.1177/0959353506067849

Lapierre S. Mothering in the context of domestic violence: The pervasiveness of a deficit model of mothering. Child \& Family Social Work. 2008; 13(4):454-463. DOI: 10.1111/j. 1365-2206.2008.00563.x

Leonard KE. Alcohol and intimate partner violence: when can we say that heavy drinking is a contributing cause of violence? Addiction. 2005; 100(4):422-425. DOI: 10.1016/j.addbeh. 2006.09.007 [PubMed: 15784050]

May V. On being a 'good' mother: The moral presentation of self in written life stories. Sociology. 2008; 42(3):470-486. DOI: 10.1177/0038038508088836

Miller WC, Anton HA, Townson AF. Measurement properties of the CESD scale among individuals with spinal cord injury. Spinal Cord. 2008; 46:287-292. DOI: 10.1038/sj.sc.3102127 [PubMed: 17909558]

Miller, WR., Rollnick, S. Motivational interviewing: Helping people change. New York: Guilford Press; 2012.

Mulia N, Schmidt L, Bond J, Jacobs L, Korcha R. Stress, social support and problem drinking among women in poverty. Addiction. 2008; 103(8):1283-1293. DOI: 10.1111/j.1360-0443.2008.02234.x [PubMed: 18855817]

Nadal KL, Griffin KE, Wong Y, Hamit S, Rasmus M. The impact of racial microaggressions on mental health: Counseling implications for clients of color. Journal of Counseling \& Development. 2014; 92(1):57-66. DOI: 10.1002/j.1556-6676.2014.00130.x 
Neger EN, Prinz RJ. Interventions to address parenting and parental substance abuse: Conceptual and methodological considerations. Clinical Psychology Review. 2015; 39:71-82. DOI: 10.1016/j.cpr. 2015.04.004 [PubMed: 25939033]

Padget, DK. Qualitative methods in social work research. Vol. 36. Los Angeles: Sage; 2008.

Prins A, Ouimette P, Kimerling R, Cameron RP, Hugelshofer DS, Shaw-Hegwer J, Thrailkill A, Gusman FD, Sheikh JI. The Primary Care PTSD Screen (PC-PTSD): Development and operating characteristics. Primary Care Psychiatry. 2003; 9:9-14. DOI: $10.1185 / 135525703125002360$

Raikes HA, Thompson RA. Efficacy and social support as predictors of parenting stress among families in poverty. Infant Mental Health Journal. 2005; 26(3):177-190. DOI: 10.1002/imhj.20044 [PubMed: 28682501]

Reinert DF, Allen JP. The alcohol use disorders identification test (AUDIT): A review of recent research. Alcoholism: Clinical and Experimental Research. 2002; 26(2):272-279. DOI: 10.1111/j. 1530-0277.2002.tb02534.x

Rhodes KV, Cerulli C, Dichter ME, Kothari CL, Barg FK. I didn't want to put them through that: The influence of children on victim decision-making in intimate partner violence cases. Journal of Family Violence. 2010; 25(5):485-493. DOI: 10.1007/s10896-010-9310-z

Rhodes KV, Rodgers M, Sommers M, Hanlon A, Chittams J, Doyle A, Datner E, Crits-Christoph P. Brief motivational intervention for intimate partner violence and heavy drinking in the emergency department: a randomized clinical trial. JAMA: Journal of American Medical Association. 2015; 314(5):466-477. DOI: 10.1001/jama.2015.8369

Rhodes KV, Rodgers M, Sommers M, Hanlon A, Crits-Christoph P. The social health intervention project (SHIP): Protocol for a randomized controlled clinical trial assessing the effectiveness of a brief motivational intervention for problem drinking and intimate partner violence in an urban emergency department. BMC Emergency Medicine. 2014; 14(10):1-13. DOI: 10.1186/1471-227X-14-1 [PubMed: 24423426]

Rhodes, T., Wagner, K., Strathdee, SA., Shannon, K., Davidson, P., Bourgois, P. Rethinking social epidemiology. Springer; Netherlands: 2012. Structural violence and structural vulnerability within the risk environment: theoretical and methodological perspectives for a social epidemiology of HIV risk among injection drug users and sex workers; p. 205-230.

Ritchie, J., Spencer, L. Qualitative data analysis for applied policy research. In: Huberman, AM., Miles, MB., editors. The qualitative researcher's companion. Thousand Oaks, CA: Sage Publications, Inc; 2002. p. 305-329.

Roberts DE. Racism and patriarchy in the meaning of motherhood. Journal of Gender, Social Policy \& the Law. 1992; 1(1):1-38.

Strauss, A., Corbin, J. Grounded theory methodology: An overview. In: Denzin, NK., Lincoln, YS., editors. Handbook of qualitative research. Thousand Oaks, CA: Sage Publications, Inc; 1994. p. 273-285.

Straus MA, Douglas EM. A short form of the Revised Conflict Tactics Scales, and typologies for severity and mutuality. Violence and Victims. 2004; 19(5):507-520. [PubMed: 15844722]

Substance Abuse and Mental Health Services Administration. National Survey on Drug Use and Health: Summary of national findings. Rockville, MD: Substance Abuse and Mental Health Services Administration; 2011. NSDUH series H-44, HHS publication no. (SMA) 12-4713

Trotter JL, Allen NE. The good, the bad, and the ugly: Domestic violence survivors' experiences with their informal social networks. American Journal of Community Psychology. 2009; 43(3-4):221231. DOI: 10.1007/s10464-009-9232-1 [PubMed: 19333750]

US Department of Health and Human Services. Helping patients who drink too much: a clinician's guide. National Institutes of Health. National Institute on Alcohol Abuse and Alcoholism. NIH Publication; 2005. 07-3769

Umberson D. Family status and health behaviors: Social control as a dimension of social integration. Journal of Health and Social Behavior. 1987; 28(3):306-319. [PubMed: 3680922]

Vatnar SKB, Bjørkly S. An interactional perspective of intimate partner violence: An in-depth semistructured interview of a representative sample of help-seeking women. Journal of Family Violence. 2008; 23(4):265-279. DOI: 10.1007/s10896-007-9150-7 
Vesga-Lopez O, Blanco C, Keyes K, Olfson M, Grant BF, Hasin DS. Psychiatric disorders in pregnant and postpartum women in the United States. Archives of General Psychiatry. 2008; 65(7):805815. DOI: 10.1001/archpsyc.65.7.805 [PubMed: 18606953]

White, M., Epston, D. Narrative means to therapeutic ends. New York, NY: W. W. Norton \& Company; 1990.

Wilkins, WL. Social stress and illness in industrial society. In: Gunderson, EKE., Rahe, RH., editors. Life stress and illness. Springfield, IL: Charles C. Thomas Publisher; 1974. p. 242-254.

Wilsnack SC, Klassen AD, Schur BE, Wilsnack RW. Predicting onset and chronicity of women's problem drinking: a five-year longitudinal analysis. American Journal of Public Health. 1991; 81(3):305-318. DOI: 10.2105/AJPH.81.3.305 [PubMed: 1994739]

Wilsnack SC, Wilsnack RW. International gender and alcohol research: Recent findings and future directions. Alcohol Research and Health. 2002; 26(4):245-250. [PubMed: 12875033] 


\section{Table 1}

Demographics $(\mathrm{n}=32)$

\begin{tabular}{|c|c|c|}
\hline Variable & & $\mathbf{N}(\%)$ \\
\hline Age & Mean (STD) & $30.3(5.7)$ \\
\hline \multirow[t]{3}{*}{ Number of Children $(<18)$ in Household } & Mean (STD) & $2.4(2.3)$ \\
\hline & 1 to 2 & $20(62.5)$ \\
\hline & 3 or more & $12(37.5)$ \\
\hline \multirow[t]{3}{*}{ Level of Education Completed } & Some High School & $8(25.0)$ \\
\hline & High School Graduate & $11(6.3)$ \\
\hline & Some College/College Graduate & $13(44.8)$ \\
\hline \multirow[t]{5}{*}{ Household Income } & Under $\$ 10,000$ & $8(25.8)$ \\
\hline & $\$ 10,000-19,999$ & $11(35.5)$ \\
\hline & $\$ 20,000-49,999$ & $1135.5)$ \\
\hline & $\$ 50,000$ and Over & $1(3.2)$ \\
\hline & Missing/Unknown & $1(3.2)$ \\
\hline \multirow[t]{2}{*}{ Employment $^{a}$ (out of home) } & No & $17(53.1)$ \\
\hline & Yes & $15(46.9)$ \\
\hline \multirow[t]{3}{*}{ Marital Status } & Single & $24(75.0)$ \\
\hline & Married & $4(12.5)$ \\
\hline & Divorced/Widowed/Separated & $4(12.5)$ \\
\hline \multirow[t]{4}{*}{ Race/Ethnicity } & Black & $25(78.1)$ \\
\hline & White & $1(3.1)$ \\
\hline & More than one race & $5(15.6)$ \\
\hline & Other & $1(3.1)$ \\
\hline \multirow[t]{3}{*}{ Chief Complaint for ED visit } & Injury & $3(9.4)$ \\
\hline & Medical & $23(71.9)$ \\
\hline & GYN/Urinary & $6(18.8)$ \\
\hline
\end{tabular}

a Employed out of home; 2 women indicated that they were full-time homemakers. 


\section{Table 2}

Study Eligibility and Other Psychosocial Risks. $(n=32)$

\begin{tabular}{|c|c|c|}
\hline \multicolumn{3}{|l|}{ Variable } \\
\hline \multicolumn{3}{|l|}{ CTS2S Score ${ }^{a}$} \\
\hline Mean (STD) & 16.9 & $(11.0)$ \\
\hline \multicolumn{3}{|l|}{ AUDIT Score $b$} \\
\hline Mean (STD) & 11.8 & $(6.9)$ \\
\hline \multicolumn{3}{|l|}{ Eligibility Criteria, $\mathrm{N}(\%)^{\mathcal{c}}$} \\
\hline Severe IPV only & 7 & $(21.9)$ \\
\hline Harmful/Hazardous Drinking only & 16 & $(50.0)$ \\
\hline Severe IPV \& Harmful/Hazardous Drinking & 9 & $(28.1)$ \\
\hline \multicolumn{3}{|l|}{ Illicit Drug Use, No. (\%) } \\
\hline Illegal drugs (including Marijuana) - Yes & 15 & $(46.9)$ \\
\hline Illegal drugs (not including Marijuana) -Yes & 6 & $(18.8)$ \\
\hline Prescription Drug Misuse - Yes & 4 & $(12.5)$ \\
\hline \multicolumn{3}{|l|}{ Other Mental Health Indicators, N (\%) } \\
\hline Depression $^{d}$ & 31 & $(96.9)$ \\
\hline $\mathrm{PTSD}^{e}$ & 17 & $(53.1)$ \\
\hline Childhood Sexual Abuse & 18 & $(56.3)$ \\
\hline \multicolumn{3}{|l|}{${ }^{a}$ CTS2S Assessment (CTS2S Score: 0 to 96) } \\
\hline \multicolumn{3}{|l|}{${ }^{b}$ AUDIT Assessment (AUDIT Score 0 to 40) } \\
\hline \multicolumn{3}{|c|}{$\begin{array}{l}\text { Eligible participants had to meet at least one of these criteria: a score of } 1 \text { or more on severe IPV specific items; an AUDIT total score of } 8 \text { or } \\
\text { more indicating harmful/hazardous drinking. }\end{array}$} \\
\hline \multicolumn{3}{|l|}{${ }^{d}{ }_{\text {CES-D10; Score 0-30; 10+ Depressed }}$} \\
\hline
\end{tabular}

